\title{
Modelling vitamin D status due to oral intake and sun exposure in an adult British population
}

\author{
Brian L. Diffey \\ Dermatological Sciences, Institute of Cellular Medicine, University of Newcastle, Newcastle upon Tyne NE2 4HH, UK \\ (Submitted 3 August 2012 - Final revision received 8 November 2012 - Accepted 9 November 2012 - First published online 23 January 2013)
}

\section{Abstract}

A mathematical model is described for estimating changes in plasma 25-hydroxyvitamin D (25(OH)D) levels throughout the year as a consequence of varying the oral intake of vitamin $\mathrm{D}$ and the behaviour outdoors of white British adults resident in different regions of the UK. The model yields seasonal and geographical patterns of $25(\mathrm{OH}) \mathrm{D}$ concentrations that agree closely with observational studies. Use of the model allows estimates to be easily made of the sun exposure and oral intake necessary to avoid vitamin D deficiency in defined proportions of the population, as well as strategies that would lead to vitamin D sufficiency throughout the year. The analysis demonstrates that addressing concerns about insufficient vitamin D levels, especially during the winter, may be achieved by modifying oral vitamin D intake over the winter, increasing summer sun exposure or a combination of both.

\section{Key words: Vitamin D: Diets: Sun exposure: Mathematical models: 25-Hydroxyvitamin D}

Low vitamin D status is linked to rickets and osteomalacia, with some evidence to suggest that it may also be implicated in a range of diseases including osteoporosis, some types of cancer, CVD, tuberculosis, multiple sclerosis and type 1 diabetes $^{(1)}$. Quite what should be the relative contributions of oral vitamin D intake and sunlight exposure to maintain and achieve an adequate vitamin D status, especially during the winter in 'at-risk' population groups, is not clear ${ }^{(2)}$.

The usual measure of vitamin $\mathrm{D}$ status is the circulating level of 25-hydroxyvitamin D (25(OH)D), which incorporates both vitamins $\mathrm{D}_{2}$ and $\mathrm{D}_{3}$ from oral intake (principally diet) and vitamin $\mathrm{D}_{3}$ from sun exposure. In the present study, a mathematical model is developed for estimating changes in plasma $25(\mathrm{OH}) \mathrm{D}$ levels throughout the year resulting from the oral intake of vitamin D and the behaviour outdoors of white British adults resident in different regions of the UK.

The outputs from the model developed here can be used to inform the Scientific Advisory Committee on Nutrition's risk assessment on vitamin $\mathrm{D}$ and health and may contribute towards updating dietary reference values for the British population.

\section{Methods}

The model is a development of one described previously ${ }^{(3)}$ and extended by Krzyścin et al. ${ }^{(4)}$. The principal differences between the existing model and previous ones ${ }^{(3,4)}$ are that it accounts for variable oral intake, and the uptake and release of vitamin $\mathrm{D}$ from tissue stores, and uses data from recent experimental studies to inform the biokinetic parameters.

The total plasma $25(\mathrm{OH}) \mathrm{D}$ concentration in $\mathrm{nmol} / \mathrm{l}$ on day $T$, $C_{\text {total }}(T)$, comprises contributions from both oral and solar sources, and is the sum of the concentration on the previous day, $C_{\text {total }}(T-1)$, and the change in $25(\mathrm{OH}) \mathrm{D}$ between day $T$ and $T-1$, due to oral intake and sun exposure. This is expressed mathematically as:

$$
\begin{aligned}
C_{\text {total }}(T)= & C_{\text {total }}(T-1)+\left(C_{\text {oral }}(T)-C_{\text {oral }}(T-1)\right) \\
& +F(T) \times\left(C_{\text {sun }}(T)-C_{\text {sun }}(T-1)\right) .
\end{aligned}
$$

The plasma $25(\mathrm{OH}) \mathrm{D}$ concentration due to the diet and/or supplements on day $T, C_{\text {oral }}(T)$, is the consequence of oral intake $O(t)$ on all previous days $t$ weighted according to a response function $\left(R_{\text {oral }}(t)\right)$ that represents the plasma $25(\mathrm{OH}) \mathrm{D}$ concentration $t$ days after a single oral dose. This can be expressed as:

$$
C_{\text {oral }}(T)=\sum_{t=1}^{T} O(t) \times R_{\text {oral }}(T-t+1) .
$$

The plasma $25(\mathrm{OH}) \mathrm{D}$ concentration due to sunlight on day $T, C_{\text {sun }}(T)$, is the consequence of sun exposure $E(t)$ on all previous days $t$ weighted according to the area of exposed

Abbreviations: 25(OH)D, 25-hydroxyvitamin D; BSA, body surface area; SED, standard erythema dose.

Corresponding author: Brian L. Diffey, email brian.diffey@ncl.ac.uk 
skin $(A(t))$ on day $t$, and a response function $\left(R_{\mathrm{UV}}(t)\right)$ that represents the plasma $25(\mathrm{OH}) \mathrm{D}$ concentration $t$ days after a single solar UV exposure, and is expressed as:

$$
C_{\mathrm{sun}}(T)=\sum_{t=1}^{T} E(t) \times A(t) \times R_{\mathrm{UV}}(T-t+1) .
$$

The factor $F(T)$ accounts for the observation that changes in plasma $25(\mathrm{OH}) \mathrm{D}$ concentration induced by a given UV exposure are more effective for subjects having lower initial $25(\mathrm{OH}) \mathrm{D}$ concentrations. Bogh et al. ${ }^{(5)}$ exposed $24 \%$ of the body surface area (BSA) of fifty subjects with a wide range in baseline 25(OH)D levels to a fixed dose of UVB. They found that the increase in $25(\mathrm{OH}) \mathrm{D}$ levels after UVB exposure was negatively correlated with baseline $25(\mathrm{OH}) \mathrm{D}$ levels, and regression analysis applied to their data gave the following expression:

$$
F(T)=\exp \left(-0.01 \times C_{\text {total }}(T-1)\right)
$$

The boundary condition is that $C_{\text {oral }}(0), C_{\text {sun }}(0)$ and hence $C_{\text {total }}(0)$ are equal to zero. Since plasma $25(\mathrm{OH}) \mathrm{D}$ levels following a single UV exposure and/or a single oral dose fall slowly, results are always shown for year 4 by which time the relative year-to-year change is less than $1.5 \%$.

The model, which does not differentiate between sex, is constructed within an Excel spreadsheet using standard Excel functions. Tabular and graphical display of the daily variation of plasma $25(\mathrm{OH}) \mathrm{D}$ throughout the year is immediate following the user's choice of input variables, such as time and behaviour outdoors and/or oral intake. The spreadsheet is available from the author on request.

\section{Personal sun exposure}

Our sun exposure is both adventitious, such as casual exposure during the working week, and elective during our recreational exposure at weekends and on holiday. The daily personal sun exposure on weekdays $\left(E_{\mathrm{wd}}\right)$ for a specific geographical location and month is determined using a simple behavioural model ${ }^{(6)}$ such that the UV exposure to sunexposed vertical body sites, such as the face, is calculated as:

$$
E_{\mathrm{wd}}=<\mathrm{UV}>\times \mathrm{EF}_{\mathrm{wd}} \times\left(1-\left(1-b_{\mathrm{wd}} / H\right)^{2}\right) \quad \mathrm{SED},
$$

where $\langle\mathrm{UV}\rangle$ is the mean daily ambient erythemal UV in standard erythema doses (SED) (the $\operatorname{SED}^{(7)}$ is a measure of erythemally effective UV; it requires an exposure of about $2-5$ SED of sun exposure to result in the minimal reddening of unacclimatised white skin $8-24$ h later) averaged over the month; $\mathrm{EF}_{\mathrm{wd}}$ is the exposure fraction, i.e. the fraction of ambient UV received on normally exposed sites and is a consequence of posture and the surrounding environment; $b_{\mathrm{wd}}$ are the hours per $\mathrm{d}$ spent outside on weekdays; $H$ is the hours of daylight averaged over each day during the month, calculated using an established astronomical equation $^{(6)}$. In order to maintain a simple approach to modelling, it is assumed that the hours spent outside $b_{\mathrm{wd}}$ are symmetrical about the solar noon and that the irradiance of solar erythemal UV exhibits a triangular distribution between the sunrise and the sunset, peaking at solar noon, the latter assumption being well supported from the diurnal variation of erythemal UV at different latitudes ${ }^{(6)}$.

Personal sun exposure on weekend days is expressed similarly:

$$
E_{\mathrm{we}}=<\mathrm{UV}>\times \mathrm{EF}_{\mathrm{we}} \times\left(1-\left(1-h_{\mathrm{we}} / H\right)^{2}\right) \quad \mathrm{SED},
$$

where $\mathrm{EF}_{\mathrm{we}}$ is the exposure fraction received on weekends, and $b_{\text {we }}$ are the hours per $\mathrm{d}$ spent outside during weekends.

For indoor workers, whose time spent outdoors during weekdays is generally in an urban environment, exposed sites such as the face and hands typically receive about $0 \cdot 15$ of the ambient UV that is incident on an unshaded, horizontal surface ${ }^{(6)}$ due to the combined effect of body geometry, random orientation with respect to the sun, partial obstruction of the sky, and possibly direct shading of sunlight by nearby buildings.

At weekends, especially during recreational exposure, more time may be spent away from urban areas where a much greater part of the sky will be visible and the shade of direct sunlight less frequent. Consequently, the weekend exposure fraction $\mathrm{EF}_{\text {we }}$ was increased to $0 \cdot 25$.

It is evident that there is an appreciable variation in the time spent outdoors during a specific exposure period (e.g. summer weekends) by habitués. The results of a metaanalysis on time spent outdoors during the summer season $^{(8)}$ indicated that weekday and weekend exposures are positively skewed with median times per $\mathrm{d}$ spent outdoors close to 1 and $1.5 \mathrm{~h}$, respectively.

The personal sun exposure calculated here does not take into account protective behaviours such as sunscreen use or wearing a hat that result in shadow over the face; such behaviour would modify the UV dose absorbed in the skin, and hence the vitamin D synthesis.

\section{Exposed skin}

During the winter, it is generally just the hands, face and neck that are exposed, equivalent to about $6-10 \%$ of the $\mathrm{BSA}^{(9)}$. In the summer, there will be a tendency for some people to expose their arms during the working week, which together with the face, neck and hands comprises about $15-20 \%$ of the BSA. Also, during summer weekends and holidays, the lower legs will often be exposed resulting in about $30 \%$ of the BSA.

For typical personal daily doses (generally $<1$ SED) and exposed body surfaces (generally $<20 \%$ ) encountered in day-to-day life, which is the nature of exposure reflected by the model, the increase in $25(\mathrm{OH}) \mathrm{D}$ has been shown to be proportional to the product of UV exposure and the fraction of exposed $\mathrm{BSA}^{(10)}$; although for significant ( $>40 \%$ ) exposed BSA and UV exposures encountered during extended periods of recreational exposure in the sun such as occurs on vacation and where erythema is often a consequence, the assumption that vitamin D synthesis increases in proportion to the product of dose and area is invalid ${ }^{(10)}$. 


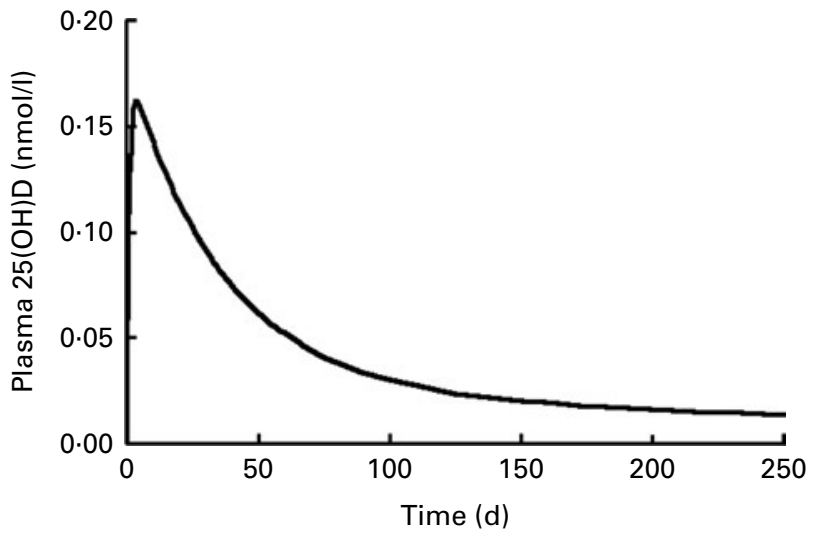

Fig. 1. Time-varying concentration of plasma 25-hydroxyvitamin D $(25(\mathrm{OH}) \mathrm{D})$ in response to a single solar UV exposure of 1 standard erythema dose (SED) UV to $1 \%$ of the body surface area calculated according to equation 7 .

\section{The UV response function $R_{U V}(t)$}

The UV response function $\left(R_{\mathrm{UV}}(t)\right)$ represents the plasma $25(\mathrm{OH}) \mathrm{D}$ concentration $t$ days after a single UV exposure, and is described here by a two-compartment model that accounts for the plasma uptake, plasma clearance and uptake and clearance by tissue stores of $25(\mathrm{OH}) \mathrm{D}$, by the following expression:

$$
\begin{aligned}
R_{\mathrm{UV}}(t)= & A\left((1-f) \times 2^{-t / \beta}\right. \\
& \left.+f \times 2^{-t / \gamma}-2^{-t / \alpha}\right)(\mathrm{nmol} / 1 \text { per SED })
\end{aligned}
$$

where $A$ is a scaling factor such that $R_{\mathrm{UV}}(t)$ represents plasma $25(\mathrm{OH}) \mathrm{D}$ concentration per SED for $1 \%$ of BSA exposed; $f$ is the fraction of synthesised vitamin D stored in tissue; $\alpha, \beta$ and $\gamma$ are the half-times for plasma uptake, plasma clearance and tissue store clearance, respectively.

Following a single whole-body exposure of eleven healthy volunteers on a commercial sunbed (UVB comprised $2 \%$ of the total UV emission), blood samples were analysed for $25(\mathrm{OH}) \mathrm{D}$ at baseline, $15 \mathrm{~min}, 1,2,4,6 \mathrm{~h}, 1,2,3$ and $7 \mathrm{~d}$ post-exposure $^{(11)}$. The resulting time course showed a rapid rise followed by a steady state between 2 and $7 \mathrm{~d}$ and by non-linear regression analysis on these data, the half-time for uptake $(\alpha)$ was estimated as $0.6 \mathrm{~d}$.

The half-life $(\beta)$ for plasma clearance of $25(\mathrm{OH}) \mathrm{D}$ has been reported as 2 weeks $^{(12)}$ and $3-4$ weeks $^{(13)}$. A more recent estimate ${ }^{(14)}$ reported that the half-life of plasma $25(\mathrm{OH}) \mathrm{D}$ is about $25 \mathrm{~d}$, and so we adopt this value for $\beta$.

The dynamics of vitamin D storage in body tissues and re-entry into the circulation remain poorly understood, although it has been suggested that tissue storage can last for months or even years ${ }^{(15)}$. Consequently, a two-compartment model for the time course of plasma 25(OH)D is used. To obtain estimates for the fraction $(f)$ of synthesised vitamin $\mathrm{D}$ stored in tissue and for the half-time $(\gamma)$ for tissue store clearance, data on groups who have been deprived of UV radiation for several months were used. The subsequent analysis (see below) resulted in estimates of $0 \cdot 15$ for the fraction $(f)$ and a half-time $(\gamma)$ for tissue store clearance of $250 \mathrm{~d}$.
Finally, data from an intervention study were used to estimate the scaling factor $A$. This study ${ }^{(16)}$, carried out over the winter, involved 120 white Caucasians aged 20-60 years who received a sun equivalent dose of $1 \cdot 1$ SED three times per week for 6 weeks while wearing T-shirt and shorts, resulting in about $30 \%$ of BSA irradiated. Plasma $25(\mathrm{OH}) \mathrm{D}$ was measured at baseline and again at weekly intervals until the end of the study. The model was run using the appropriate inputs ( 1.1 SED three times per week and 30\% BSA) and the scaling factor optimised to obtain the best fit, which resulted in a value of $A$ of $0 \cdot 18 \mathrm{nmol} / 1$ per SED per cent of BSA.

So using data from a number of independent experimental studies, we obtain values of the biokinetic parameters $A, f, \alpha$, $\beta$ and $\gamma$; the response function, $R_{\mathrm{Uv}}(t)$, calculated using these values is shown in Fig. 1.

\section{The oral intake response function $\mathrm{R}_{\text {oral }}(\mathrm{t})$}

The time course of $25(\mathrm{OH}) \mathrm{D}$ was measured over a 4-month period in a group of thirty healthy, community-dwelling, predominantly white men and women (age range 27-84 years) following a single oral dose of $2500 \mu \mathrm{g}$ of cholecalciferol ${ }^{(17)}$. The results from this study are shown by the data points in Fig. 2 and the solid line is given by the expression:

$$
2500 \times R_{\text {oral }}(t) \quad(\mathrm{nmol} / \mathrm{l}),
$$

where $R_{\text {oral }}(t)$ is a response function that represents plasma $25(\mathrm{OH}) \mathrm{D}$ concentration per $\mu \mathrm{g}$ intake. We assume that the kinetics of plasma and tissue clearance of $25(\mathrm{OH}) \mathrm{D}$ are the same irrespective of whether the source is oral or UV, and so we take $R_{\text {oral }}(t)$ to have the same form as was used above for the UV response function $R_{\mathrm{UV}}(t)$ :

$$
\begin{aligned}
R_{\text {oral }}(t)= & S \times\left((1-f) \times 2^{-t / \beta}\right. \\
& \left.+f \times 2^{-t / \gamma}-2^{-t / \alpha}\right) \quad(\mathrm{nmol} / 1 \text { per } \mu \mathrm{g}),
\end{aligned}
$$

where $S$ is a scaling factor and $\alpha^{\prime}$ is the half-time for uptake from oral intake, which is not necessarily the same as for UV synthesis. We take the remaining terms $f, \beta$ and $\gamma$ to be numerically identical to those derived for the UV response function. Using the Solver capability of Excel, $S$ and $\alpha^{\prime}$ were determined to be $0.018 \mathrm{nmol} / 1$ per $\mu \mathrm{g}$ and $1.5 \mathrm{~d}$, respectively. It may be seen from Fig. 2 that the modelled function given by equation 9 is commensurate with the uncertainties associated with the experimental data.

The steady-state cholecalciferol input required to achieve an equilibrium plasma $25(\mathrm{OH}) \mathrm{D}$ concentration is determined as:

$$
\begin{aligned}
& \int_{0}^{\infty} R_{\text {oral }}(t) \times \mathrm{dt} \\
& \quad=S \times\left((1-f) \beta+f \gamma-\alpha^{\prime}\right) / \ln (2)(\mathrm{nmol} / 1 \text { per } \mu \mathrm{g})
\end{aligned}
$$

which equals $1.52 \mathrm{nmol} / 1$ per $\mu$ g. Other authors have estimated equilibrium values (in $\mathrm{nmol} / \mathrm{l}$ per $\mu \mathrm{g}$ ) of $0.56^{(18)}$ $0 \cdot 70^{(19)}$ and $1 \cdot 15^{(18)}$, with six studies ${ }^{(20-25)}$ yielding values in the range $1 \cdot 6-2 \cdot 2$. The median value of these nine estimates is $1.9 \mathrm{nmol} / \mathrm{l}$ per $\mu \mathrm{g}$, resulting in a revised value of $S$ of 


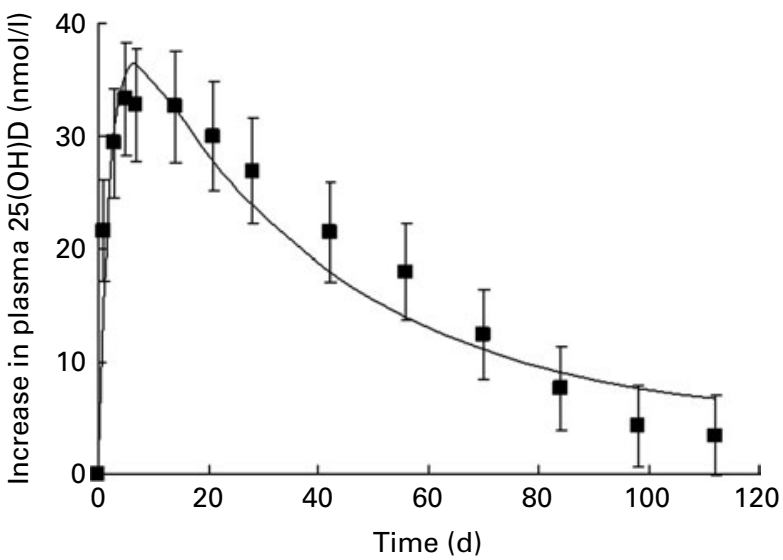

Fig. 2. Time-varying concentration ( $\pm 1 \mathrm{SEM}$ ) of plasma 25-hydroxyvitamin $D$ $(25(\mathrm{OH}) \mathrm{D})$ following a single oral dose of $2500 \mu \mathrm{g}$ cholecalciferol (modified from llahi et al. $\left.{ }^{(17)}\right)$. Response expressed by equation $8(-)$.

$0.023 \mathrm{nmol} / \mathrm{l}$ per $\mu \mathrm{g}$; this exemplary value will be used henceforth in equation 9 .

\section{Results}

\section{Modelled seasonal variation of 25-hydroxyvitamin $D$} in a British population

The habitual mean daily dietary vitamin D in British people is generally in the range $2-4 \mu \mathrm{g}^{(26)}$, and calculations were carried out using an exemplary oral vitamin D intake $(O(t)$; equation 2) of $3 \mu \mathrm{g} / \mathrm{d}$. Time spent outdoors, exposure fraction (reflecting urban or non-urban environment) and area of exposed skin at different times of the year that could be regarded as representative of the typical behaviour of British indoor workers are summarised in Table 1.

All results presented here assume a British population and ambient UV data were available in approximately $2^{\circ}$ latitude steps from southern England (latitude $50^{\circ} \mathrm{N}$ ) to the Shetland Islands (latitude $60^{\circ} \mathrm{N}$ ). Monthly values of mean daily ambient UV for each region were averaged over the 16-year period (1995-2011) and used as estimates for $<U V>$ (Table 2).

We assume that weekday exposure for much of the year is limited to the hands, face and neck (10\% BSA) except for the months of June, July, August and September where the BSA is increased to $15 \%$, reflecting that many people will be exposing forearms in addition. For weekend exposure from June through to September, the BSA is taken as $15-20 \%$ to reflect the opportunity taken by some people to expose arms and legs in addition to normally exposed sites. The resulting variation of plasma $25(\mathrm{OH}) \mathrm{D}$ throughout the year is shown by the solid line in Fig. 3, calculated assuming ambient UV typical of the English Midlands, which is the region corresponding to the centre of population of Great Britain.

The impact of sun-avoidance behaviour, which we take to be times spent outdoors per d of 30 and 45 min for weekdays and weekends, respectively, is illustrated by the lower dashed line in Fig. 3. Similarly, sun-seeking behaviour, which we take to be 2 and 3 h spent outdoors per d for weekdays and weekends, respectively, is illustrated by the upper dashed line in Fig. 3.

Also shown in Fig. 3 are the geometric mean monthly plasma $25(\mathrm{OH}) \mathrm{D}$ concentrations measured by Hyppönen \& Power ${ }^{(27)}$. These authors measured plasma 25(OH)D in over 7000 white British people from the 1958 birth cohort when they were 45 years of age during the period September 2002 to April 2004. The modelled and measured data both show a minimum in late February/early March and a peak in late August/early September with a close agreement between the measured data and that calculated for 'typical' behaviour.

It is of note that a mean daily dietary vitamin $\mathrm{D}$ of $3 \mu \mathrm{g}$, combined with a median equilibrium value of $1.9 \mathrm{nmol} / 1$ per $\mu \mathrm{g}$ (range $0 \cdot 56-2 \cdot 2 \mathrm{nmol} / 1$ per $\mu \mathrm{g}^{(17-25)}$ ), results in a contribution of diet to overall $25(\mathrm{OH}) \mathrm{D}$ status of about $6 \mathrm{nmol} / 1$ (calculated range $1.7-6.6 \mathrm{nmol} / \mathrm{l}$ ), suggesting that even in the winter when levels fall to about $30-40 \mathrm{nmol} / 1$, storage and release of vitamin $\mathrm{D}$ from tissue due to summer sun exposure is the major factor in maintaining $25(\mathrm{OH}) \mathrm{D}$ levels throughout the year.

The large study carried out by Hyppönen \& Power ${ }^{(27)}$ showed there was a south-north gradient in the mean plasma $25(\mathrm{OH}) \mathrm{D}$ concentrations, a finding also supported by the model using the behavioural characteristics in Table 1 and the ambient UV data in Table 2, as illustrated in Fig. 4.

\section{Changes in 25-hydroxyvitamin D in UV-deprived groups}

The groups chosen were submariners ${ }^{(28-33)}$ and astronauts on a long-duration mission aboard the Russian Mir space station $^{(34)}$. In the submariner studies, $25(\mathrm{OH}) \mathrm{D}$ was assayed immediately before the start of the patrol, just before the

Table 1. Variables that are assumed to reflect representative behaviour of British people outdoors

\begin{tabular}{|c|c|c|c|c|c|c|c|c|c|c|c|c|}
\hline & Jan & Feb & Mar & Apr & May & Jun & Jul & Aug & Sep & Oct & Nov & Dec \\
\hline \multicolumn{13}{|l|}{ Weekdays } \\
\hline Time outside per weekday $(\mathrm{h})^{\star}$ & 1.0 & 1.0 & 1.0 & 1.0 & 1.0 & 1.0 & 1.0 & 1.0 & 1.0 & 1.0 & 1.0 & 1.0 \\
\hline Exposure fraction $\dagger$ & 0.15 & 0.15 & 0.15 & 0.15 & 0.15 & 0.15 & 0.15 & 0.15 & 0.15 & 0.15 & 0.15 & 0.15 \\
\hline BSA exposed (\%) & 10 & 10 & 10 & 10 & 10 & 15 & 15 & 15 & 15 & 10 & 10 & 10 \\
\hline \multicolumn{13}{|l|}{ Weekends } \\
\hline Time outside per weekend day $(h)^{\star}$ & 1.5 & 1.5 & 1.5 & 1.5 & 1.5 & 1.5 & 1.5 & 1.5 & 1.5 & 1.5 & 1.5 & 1.5 \\
\hline Exposure fractiont & 0.25 & 0.25 & 0.25 & 0.25 & 0.25 & 0.25 & 0.25 & 0.25 & 0.25 & 0.25 & 0.25 & 0.25 \\
\hline BSA exposed (\%) & 10 & 10 & 10 & 10 & 10 & 15 & 20 & 20 & 15 & 10 & 10 & 10 \\
\hline
\end{tabular}

BSA, body surface area

${ }^{*}$ From Diffey ${ }^{(8)}$

†From Diffey ${ }^{(6)}$ 
Table 2. Average daily ambient solar UV radiation (in standard erythema doses; SED) measured at different locations in Great Britain (courtesy of the Health Protection Agency)

\begin{tabular}{|c|c|c|c|c|c|c|c|c|c|c|c|c|c|}
\hline Region & Latitude $\left({ }^{\circ} \mathrm{N}\right)$ & Jan & Feb & Mar & Apr & May & Jun & Jul & Aug & Sep & Oct & Nov & Dec \\
\hline Southern England & 50 & $1 \cdot 1$ & $2 \cdot 7$ & $6 \cdot 6$ & $13 \cdot 6$ & $20 \cdot 2$ & $25 \cdot 7$ & $23 \cdot 6$ & 20.5 & $13 \cdot 3$ & 5.5 & 1.9 & 0.9 \\
\hline Midlands/Wales & 52 & 0.9 & $2 \cdot 4$ & 5.9 & $12 \cdot 1$ & $18 \cdot 7$ & $23 \cdot 5$ & $22 \cdot 4$ & 18.5 & 11.5 & 4.9 & 1.6 & 0.7 \\
\hline Northern England & 54 & 0.7 & $2 \cdot 0$ & $5 \cdot 3$ & $11 \cdot 0$ & $17 \cdot 0$ & $20 \cdot 4$ & $20 \cdot 1$ & $16 \cdot 2$ & 9.9 & $4 \cdot 1$ & $1 \cdot 2$ & 0.6 \\
\hline Southern Scotland & 56 & 0.4 & 1.5 & $4 \cdot 2$ & 9.4 & $15 \cdot 7$ & $18 \cdot 8$ & $17 \cdot 9$ & $13 \cdot 7$ & $8 \cdot 8$ & 3.0 & 0.9 & 0.4 \\
\hline Northern Scotland & 58 & 0.4 & $1 \cdot 2$ & 3.7 & $9 \cdot 1$ & $15 \cdot 6$ & $18 \cdot 4$ & $18 \cdot 1$ & $13 \cdot 6$ & $7 \cdot 8$ & $2 \cdot 6$ & 0.7 & 0.2 \\
\hline Shetland Islands & 60 & 0.2 & 0.9 & $3 \cdot 1$ & $7 \cdot 6$ & 13.4 & $16 \cdot 8$ & $15 \cdot 7$ & $12 \cdot 4$ & $6 \cdot 2$ & $2 \cdot 0$ & 0.4 & 0.2 \\
\hline
\end{tabular}

end of the patrol (generally 2 months) and occasionally at one or more times during the patrol. The patrols are generally deployed in the late summer when $25(\mathrm{OH}) \mathrm{D}$ levels are close to their maximum. In the case of the three astronauts, samples were taken before the start of the mission and again after 14 and $110 \mathrm{~d}$. As far as can be ascertained, in none of the studies were the subjects given high doses of supplemental vitamin D nor was their diet especially enriched in vitamin $\mathrm{D}$.

The data points in Fig. 5 show the relative 25(OH)D levels from each of the submariner studies (normalised to unity at the start of each patrol and assumed to be 1 August), as well as from the study in astronauts. The model was run for typical sun exposure (input values given in Table 1) up until the end of July and then UV exposure was set to zero for the remainder of the year. Using a regression technique, the fraction $(f)$ of synthesised vitamin D stored in tissue and the half-time $(\gamma)$ for tissue store clearance were determined to be 0.15 and $250 \mathrm{~d}$, respectively. The relative change in plasma $25(\mathrm{OH}) \mathrm{D}$ resulting from the model calculations is shown by the solid line in Fig. 5 .

It can be seen from the experimental data points in Fig. 5 that $25(\mathrm{OH}) \mathrm{D}$ levels in UV-deprived subjects fall to $50 \%$ of the values at the start of the patrols at about 100-120 d; this is considerably longer than the commonly accepted plasma clearance half-life of about $25 \mathrm{~d}$ but is well explained by combining a $25 \mathrm{~d}$ half-life with a slower $250 \mathrm{~d}$ half-life in the two-compartment model described by equation 7 . The broken line in Fig. 5 is the calculated relative variation in $25(\mathrm{OH}) \mathrm{D}$ from the start of the patrols assuming $f=0$ in equation 7 , i.e. no synthesised vitamin $\mathrm{D}$ stored in tissue.

\section{Estimating proportion of the population who are vitamin $D$ deficient}

Studies of $25(\mathrm{OH}) \mathrm{D}$ status in British people showed a wide variation about the mean at a given period within the year $^{(15,16)}$. In keeping with the findings of others ${ }^{(25,27)}$, we assume that $25(\mathrm{OH}) \mathrm{D}$ levels in a given population at a given time of year are lognormally distributed. In Table 2 of their paper, Hyppönen \& Power ${ }^{(27)}$ give average $25(\mathrm{OH}) \mathrm{D}$ values and the prevalence of hypovitaminosis $\mathrm{D}$ at three thresholds $(<25,<40$ and $<75 \mathrm{nmol} / \mathrm{l})$ stratified by season and demographic characteristics. From these data, we determine, using the Solver capability of Excel, that the lognormal standard deviation is 0.50 , and so we can estimate the proportion of people whose $25(\mathrm{OH}) \mathrm{D}$ status falls below a given threshold. For example, if we take a mean winter level of $38 \mathrm{nmol} / \mathrm{l}$, the percentage of subjects estimated to be vitamin D deficient (defined here as plasma $25(\mathrm{OH}) \mathrm{D}<25 \mathrm{nmol} / \mathrm{l}^{(35)}$ ) can be obtained using the Excel function LOGNORMDIST as:

$$
\text { LOGNORMDIST(25, } \left.\log _{\mathrm{e}}(38), 0 \cdot 50\right)=20 \% \text {. }
$$

The model was run with a dietary intake of $3 \mu \mathrm{g} / \mathrm{d}$ and the behavioural inputs given in Table 1 for women resident in southern England and northern Scotland. Fig. 6 compares the calculated and observed ${ }^{(15)}$ seasonal levels of plasma $25(\mathrm{OH}) \mathrm{D}$, while the predicted and observed ${ }^{(15)}$ prevalence of vitamin D deficiency in each season is shown in Fig. 7. It can be seen that despite the simplistic approach to modelling human behaviour, there is a good agreement between the predicted and observed seasonal changes in $25(\mathrm{OH}) \mathrm{D}$ and the prevalence of vitamin $\mathrm{D}$ deficiency.

\section{Addressing vitamin D deficiency during the winter}

A nationwide survey ${ }^{(27)}$ in the UK showed that $16 \%$ of the adult population have deficient levels of vitamin D $(<25 \mathrm{nmol} / \mathrm{l})$ during the winter and spring. We can use the model to investigate how increasing sun exposure and/or oral intake of vitamin D might lower this percentage.

There are a large number of variables that we could vary, such as the percentage of exposed BSA on weekdays and weekends for each month, or time spent outdoors during weekdays. Yet how much skin people choose to expose is constrained by ambient temperature and social norms, and the freedom to vary the time spent outdoors during weekdays is limited for most people by the demands of employment.

Consequently, we limit ourselves to two variables that people have personal control over and could choose to vary

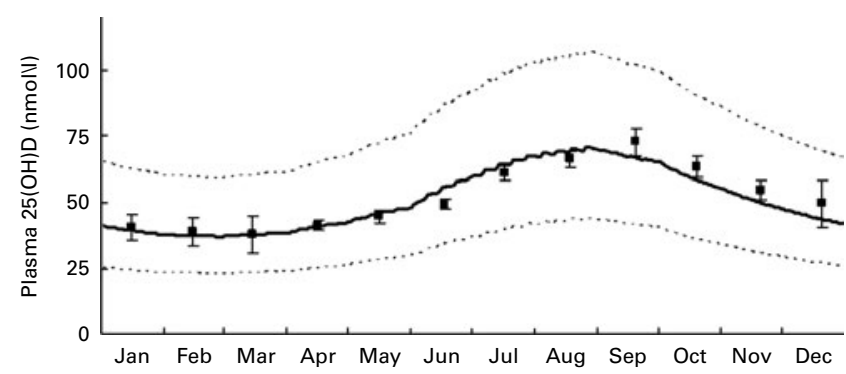

Fig. 3. Modelled annual variations in 25-hydroxyvitamin $D(25(\mathrm{OH}) \mathrm{D})$ for an oral vitamin $D$ intake of $3 \mu \mathrm{g} / \mathrm{d}$, and times per d spent outdoors during weekdays and weekends of 30 and $45 \mathrm{~min}$ (lower broken curve), 1 and $1.5 \mathrm{~h}$ (solid curve) and 2 and $3 \mathrm{~h}$ (upper broken curve). Data are geometric mean monthly $25(\mathrm{OH}) \mathrm{D}$ concentrations with $95 \% \mathrm{Cl}$ represented by vertical bars measured by Hyppönen \& Power ${ }^{(27)}$. 


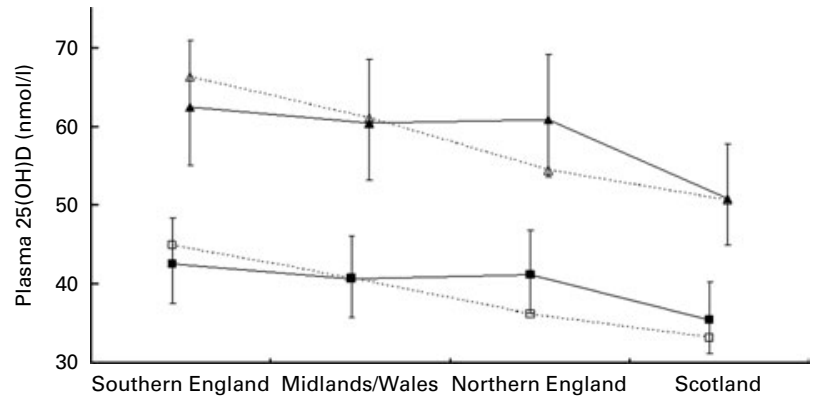

Fig. 4. Regional variation in mean 25-hydroxyvitamin $D(25(\mathrm{OH}) \mathrm{D})$ levels in British people in the winter/spring (observed values ${ }^{(27)}(-\mathbf{r})$ and calculated values (. $\square$.)) and summer/autumn (observed values ${ }^{(27)}(\boldsymbol{A}-)$ and calculated values $(\cdot-\cdot))$. The 40 th-60th percentile ranges of the observed data are represented by vertical bars.

without too much external influence: the average time spent outdoors on weekend days and supplemental intakes of vitamin $\mathrm{D}$ during the winter months.

The model was run with the behavioural inputs given in Table 1 for a white adult population resident in the English Midlands. We assume a daily dietary intake of $3 \mu \mathrm{g}$ with supplemental daily intake of vitamin D ranging from 0 to $30 \mu \mathrm{g}$ during the period November through to the end of February, and with average time spent outdoors on weekend days throughout the year ranging from 1 to $4 \mathrm{~h}$. These are mean times spent outdoors; in a given population there will be an appreciable variation about the mean due to propensity for being outside ${ }^{(8)}$. For each combination of vitamin $\mathrm{D}$ intake and average time spent outdoors at weekends, the mean $25(\mathrm{OH}) \mathrm{D}$ levels in the 4-month period November-February were estimated and subsequently the proportion of people who are vitamin D deficient $(<25 \mathrm{nmol} / \mathrm{l})$, largely as a consequence of spending less time outdoors, as:

LOGNORMDIST(25, $\log _{\mathrm{e}}($ mean winter 25(OH)D levels), 0·50).

The results are plotted in Fig. 8 where it may be seen that to achieve a vitamin $\mathrm{D}$ deficiency over the winter in less than $2.5 \%$ of the population, it would require an average of
$1.5 \mathrm{~h} / \mathrm{d}$ spent outdoors on weekends throughout the year coupled with supplemental vitamin $\mathrm{D}$ intake between November and February of $28 \mu \mathrm{g} / \mathrm{d}$, or alternatively $3 \mathrm{~h} / \mathrm{d}$ spent outdoors on average on weekends throughout the year coupled with supplemental vitamin D intake between November and February of $11 \mu \mathrm{g} / \mathrm{d}$. Keeping the average weekend outdoor exposure throughout the year to $1.5 \mathrm{~h} / \mathrm{d}$ and taking a winter vitamin D supplement of $5 \mu \mathrm{g} / \mathrm{d}$ is estimated to result in about $10 \%$ of the population being vitamin $\mathrm{D}$ deficient over the winter, a significant improvement on the estimated prevalence of $15 \%$ deficiency if no supplement is taken and the only oral intake is $3 \mu \mathrm{g} / \mathrm{d}$ from the diet.

\section{Maintaining vitamin D sufficiency throughout the year}

Inspection of Fig. 3 shows that people resident in the Midlands/Wales exhibiting typical behaviour outdoors (Table 1) are estimated to have insufficient levels of plasma 25(OH)D (defined here as plasma $25(\mathrm{OH}) \mathrm{D}<50 \mathrm{nmol} / \mathrm{l}^{(35)}$ ) from November through to May. For people living in northern Scotland, this period of insufficiency is estimated to extend for 9 months from October through to June.

We use the model to examine strategies for maintaining sufficient $25(\mathrm{OH}) \mathrm{D}$ levels (i.e. $>50 \mathrm{nmol} / \mathrm{l}$ ) throughout the year. This can be achieved by spending more time outdoors, by supplementing dietary vitamin $\mathrm{D}$ intake, or a combination of both.

Relying solely on sun exposure would require spending $1.5 \mathrm{~h} / \mathrm{d}$ outdoors on weekdays and $2.5 \mathrm{~h} / \mathrm{d}$ outdoors at weekends throughout the year (assuming ambient UV typical of Midlands/Wales), as illustrated in Fig. 9. The problem here is that devoting this amount of time spent outdoors could prove impracticable for many people, and $2.5 \mathrm{~h}$ outdoor exposure on unprotected skin at weekends, especially during the summer, could lead to sunburn and compromise skin health.

Alternatively, keeping outdoor exposure to typical values of 1 and $1.5 \mathrm{~h} / \mathrm{d}$ on weekdays and weekends ${ }^{(8)}$ but increasing oral intake to $18 \mu \mathrm{g} / \mathrm{d}(3 \mu \mathrm{g} / \mathrm{d}$ from the diet and $15 \mu \mathrm{g} / \mathrm{d}$

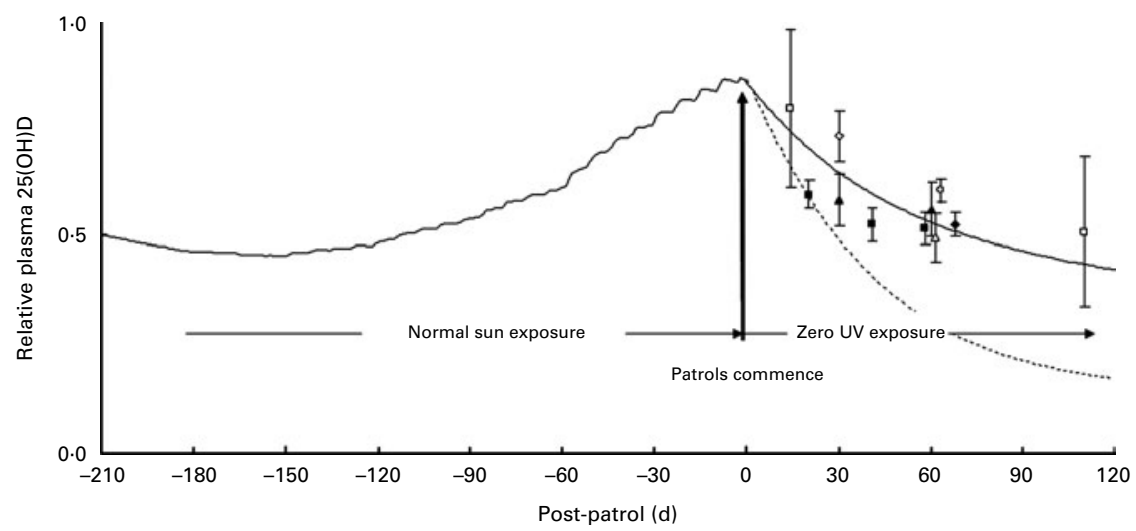

Fig. 5. Modelled relative variation in 25-hydroxyvitamin $\mathrm{D}(25(\mathrm{OH}) \mathrm{D})$ throughout the year calculated for typical outdoor behaviour up until the end of July followed by zero UV exposure for the remainder of the year $(-)$. The data points are the $25(\mathrm{OH}) \mathrm{D}$ levels relative to those at the start of the patrols in submariners

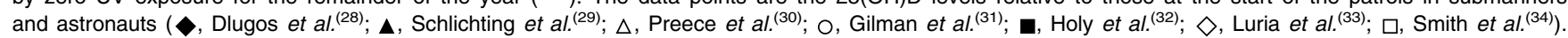
Values are means, with standard errors represented by vertical bars. Calculated relative variation in $25(\mathrm{OH}) \mathrm{D}$ from the start of the patrols assuming $f=0$ in equation 7 (---), i.e. no synthesised vitamin D stored in tissue. 


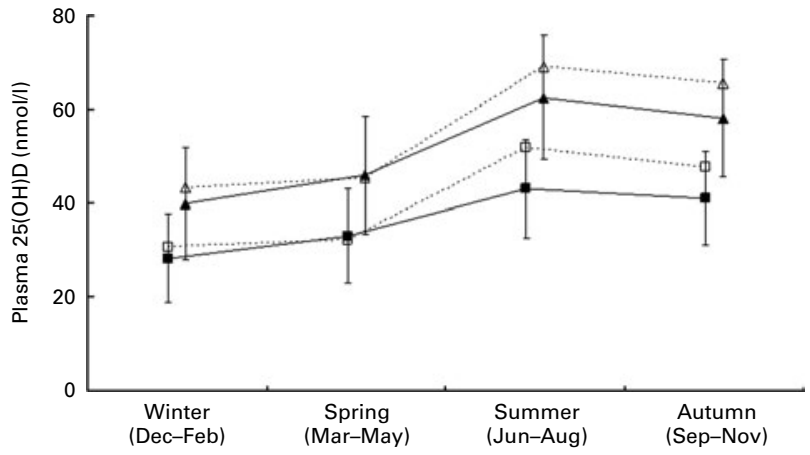

Fig. 6. Seasonal change in 25-hydroxyvitamin $D(25(\mathrm{OH}) \mathrm{D})$ in Caucasian women living in northern Scotland (observed values ${ }^{(15)}(-$ ) and calculated median values $(\square \cdot))$ and southern England (observed values ${ }^{(15)}(\boldsymbol{\star})$ and calculated median values $(\Delta))$. Observed values are medians with inter-quartile ranges represented by vertical bars.

from supplements in the 4-month period from November to February) is also predicted to maintain sufficient 25(OH)D levels throughout the year (Fig. 9). This approach is not only more likely to be adopted, but is probably safer.

\section{Discussion}

A mathematical model has been developed for estimating the variation of plasma $25(\mathrm{OH}) \mathrm{D}$ concentration throughout the year as a consequence of the oral intake of vitamin D and sun exposure of white British adults resident in different regions of the UK. Although a specific age range for using the model outputs is not given, the results may not be necessarily applicable to elderly people since the production of vitamin $\mathrm{D}$ in the skin decreases considerably with ageing.

The input variables related to ambient solar UV, time spent and behaviour outdoors, area of skin exposed and mean daily dietary vitamin D intake allow the examination of how these different factors affect seasonal variation. Although the results presented here are specific to the white British adult population, the model is readily adapted to other white populations by using appropriate dietary, ambient UV and behavioural data. For non-white populations, cognisance needs to be taken of the impact of constitutive pigmentation on vitamin D status ${ }^{(36)}$.

In the spirit of Ockham's razor, fixed values for the exposure on exposed sites relative to ambient (the exposure

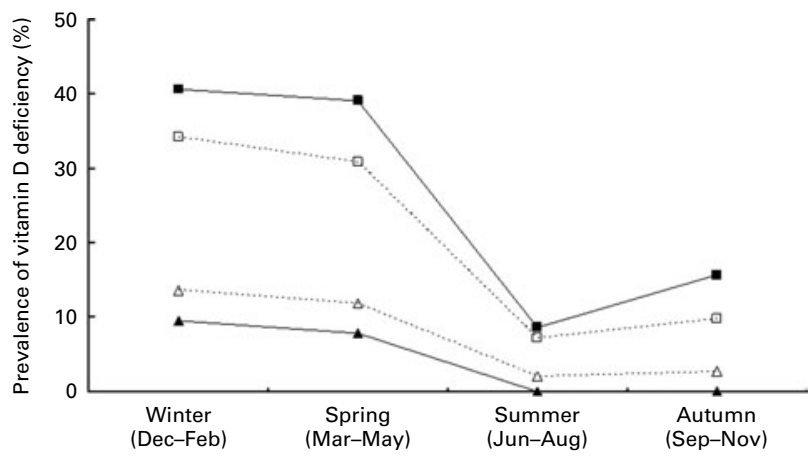

Fig. 7. Prevalence of vitamin $D$ deficiency in Caucasian women living in northern Scotland (observed values ${ }^{(15)}(-+)$ and calculated values $(\cdot \square \cdot)$ ) and southern England (observed values ${ }^{(15)}\left(\boldsymbol{\Delta}_{-}\right)$and calculated values $\left(\cdot \bullet^{-}\right)$)). fraction) were used. While the values chosen for weekday and weekend exposure of $0 \cdot 15$ and $0 \cdot 25$, respectively, are representative, they are subject to variation depending on the precise activity, for example shopping or sitting at an outdoor café facing the $\operatorname{sun}^{(37)}$. From the behavioural data given in Table 1, weekday personal exposure will be about $2-3 \%$ of ambient, with a corresponding range of $4-8 \%$ for weekend exposure; these values are in close agreement with measured data from extensive personal UV dosimetry studies carried out in Denmark ${ }^{(38)}$

Solar UV exposure has been expressed in units of erythemal radiation (i.e. SED) and not vitamin D-effective doses, which might be thought to be more appropriate. However, given the uncertainties $^{(39)}$ in the officially recognised action spectrum for the conversion of 7-dehydrocholesterol to pre-vitamin $\mathrm{D}_{3}$ in the human skin ${ }^{(40)}$, which is necessary for estimating vitamin D-effective doses, coupled with the simplistic approach taken here to modelling human behaviour, it is argued that erythemal UV exposures are an adequate surrogate for vitamin D-effective exposures, especially as they are readily available from solar UV monitoring programmes (see Table 2).

Observational studies of $25(\mathrm{OH}) \mathrm{D}$ status in British people have found mean plasma $25(\mathrm{OH}) \mathrm{D}$ averaged over the year ranging from 52 to $58 \mathrm{nmol} / 1^{(16,41,42)}$ with $\mathrm{CV}$ ranging from 37 to $48 \%^{(16,41)}$. These values are close to the overall mean $25(\mathrm{OH}) \mathrm{D}$ level of $55 \mathrm{nmol} / \mathrm{l}$ and the $\mathrm{CV}$ of $44 \%$ of the three modelled curves reflecting low, typical and high outdoor exposure, as shown in Fig. 3. It is well known that the time spent outdoors by a group of habitués is heterogeneous and shows a wide distribution ${ }^{(8)}$, and so an important contributory factor to the variance commonly observed in population studies of vitamin D status is likely to be the variation in human behaviour outdoors. There will be, of course, other factors contributing to this variance, not least genetic factors.

It is estimated that for the typical variability in the time people spend outdoors ${ }^{(8)}$, oral vitamin D supplementation of $28 \mu \mathrm{g} / \mathrm{d}$ during the period November to February is necessary to maintain $97.5 \%$ of the population above a $25(\mathrm{OH}) \mathrm{D}$ threshold of $25 \mathrm{nmol} / \mathrm{l}$ during the winter. This dosage is appreciably higher than the mean value of $8.7 \mu \mathrm{g} / \mathrm{d}$ (diet plus

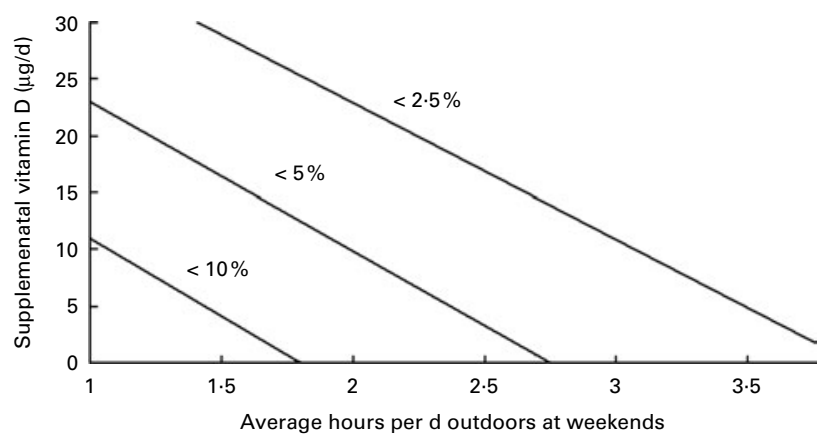

Fig. 8. Iso-prevalence plot of calculated vitamin D deficiency (25-hydroxyvita$\min \mathrm{D}(25(\mathrm{OH}) \mathrm{D})<25 \mathrm{nmol} / \mathrm{l})$. The iso-prevalence lines represent the combinations of supplemental vitamin $\mathrm{D}$ during the period November through to the end of February and average hours per $d$ spent outdoors at weekends throughout the year that would result in a given percentage of the white adult population being vitamin $\mathrm{D}$ deficient. 


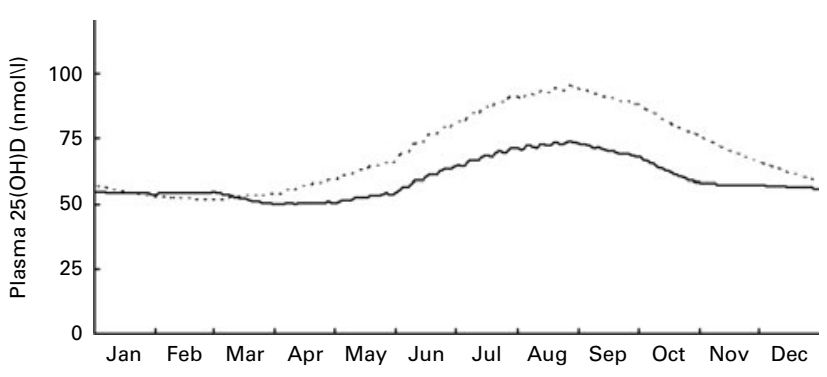

Fig. 9. Modelled annual variations in 25-hydroxyvitamin $\mathrm{D}(25(\mathrm{OH}) \mathrm{D})$ for times per d spent outdoors during weekdays and weekends of 1.5 and $2.5 \mathrm{~h}$, respectively, and an oral vitamin D intake of $3 \mu \mathrm{g} / \mathrm{d}(---)$; and times per $\mathrm{d}$ spent outdoors during weekdays and weekends of 1 and $1.5 \mathrm{~h}$, respectively, and an oral vitamin $D$ intake of $3 \mu \mathrm{g} / \mathrm{d}$ from March to October and $18 \mu \mathrm{g} / \mathrm{d}$ from November to February (-).

supplements) estimated by Cashman et al. ${ }^{(25)}$ to maintain late winter 25(OH)D levels greater than $25 \mathrm{nmol} / 1$ in $97.5 \%$ of their population. The discrepancy is explained by the much smaller variation in $25(\mathrm{OH}) \mathrm{D}$ levels in the population studied by Cashman et al. ${ }^{(25)}$ compared with the data obtained by Hyppönen \& Power ${ }^{(27)}$, which formed the basis of the present calculations (see equation 11).

From the data given in Table 2 of the paper by Cashman et $a .^{(25)}$, it can be calculated that their $25(\mathrm{OH}) \mathrm{D}$ medians and interquartile ranges lead to a lognormal standard deviation of $0 \cdot 34$, compared with a corresponding value of 0.50 from the observations of Hyppönen \& Power ${ }^{(27)}$ (see above). If the model described here is run with an oral intake of $8.7 \mu \mathrm{g} / \mathrm{d}$, the late winter $25(\mathrm{OH}) \mathrm{D}$ level is estimated to be $48.4 \mathrm{nmol} / \mathrm{l}$, and applying a lognormal standard deviation of 0.34 leads to a prevalence of deficiency $(<25 \mathrm{nmol} / \mathrm{l})$ of LOGNORMDIST(25, $\left.\log _{e}(48.4), 0.34\right)=2.6 \%$, a value very close to the $2.5 \%$ estimated by Cashman et al. ${ }^{(25)}$. For the same winter $25(\mathrm{OH}) \mathrm{D}$ level of $48.4 \mathrm{nmol} / 1$, the data in Table 2 of the paper by Hyppönen \& Power ${ }^{(27)}$ would indicate a prevalence of deficiency of LOGNORMDIST(25, $\log _{\mathrm{e}}(48.4), 0.50$ ), which is almost $10 \%$.

Although the model described here provides insights into how oral vitamin $\mathrm{D}$ intake and behaviour outdoors have an impact upon changes in population $25(\mathrm{OH}) \mathrm{D}$ status throughout the year, it is important to recognise that there are many confounding factors that will have an influence on the use of the model at an individual level; these include the rate of vitamin D production in the skin from different parts of the body, age, obesity and degree of constitutive and facultative skin pigmentation. In principle, however, the model could be extended to account for these factors given the availability of robust experimental data that could be used to inform the additional parameters required. Such data may now be coming available ${ }^{(43)}$.

Because of its simplicity and limitations, the notion that a computational model might have credibility will not be shared by everyone, especially those who prefer to avoid mathematics $^{(44)}$. Yet the idea that you can carry out all the trials necessary to decide between an infinite number of choices is, of course, untenable. Should we advise people to expose themselves to the sun every day, every other day or just at weekends? Or should we recognise that oral intake, either by the diet, supplements or a combination of both, is likely to be more effective and safer in reducing the proportion of the population who are vitamin D deficient? The analysis here indicates that the latter may be preferable (Fig. 9), even though the typical daily intake of vitamin D from food contributes less than sun exposure to average year-round 25(OH)D levels in both British Caucasian and Asian women ${ }^{(2)}$. It should be noted, however, that oral intake may not be free of risk, as we do not know the longterm health effects related to continued high oral intake compensating for the lack of solar UV especially during the winter.

Clinical trials, especially in the public health arena, are expensive, time consuming, often lack robustness and, unless designed appropriately, may furnish little information about how to improve upon interventions to improve public health. Mathematical models complement observational data in several ways. The measurements are precise and exactly repeatable. The costs are low and the timescales are short. In the context of oral intake of vitamin $\mathrm{D}$, population exposure to solar UV radiation and the subsequent plasma levels of $25(\mathrm{OH}) \mathrm{D}$, this is a very real advantage.

\section{Acknowledgements}

The author is grateful to Dr Tom Hill for his helpful comments on the manuscript, and to the Health Protection Agency, Chilton, for providing the ambient solar UV data. There are no conflicts of interest.

\section{References}

1. Holick MF (2008) Deficiency of sunlight and vitamin D. Br Med J 336, 1318-1319.

2. Ashwell MA, Stone EM, Stolte H, et al. (2010) UK Food Standards Agency Workshop Report: an investigation of the relative contribution of diet and sunlight to vitamin D status. Br J Nutr 104, 603-611.

3. Diffey BL (2010) Modelling the seasonal variation of vitamin $\mathrm{D}$ due to sun exposure. Br J Dermatol 162, 1342-1348.

4. Krzyścin JW, Jarosławski J \& Sobolewski PS (2011) A mathematical model for seasonal variability of vitamin $D$ due to solar radiation. J Photochem Photobiol B Biol 105, 106-112.

5. Bogh MKB, Schmedes AV, Philipsen PA, et al. (2010) Vitamin D production after UVB exposure depends on baseline vitamin $\mathrm{D}$ and total cholesterol but not on skin pigmentation. J Invest Dermatol 130, 546-553.

6. Diffey BL (2008) A behavioural model for estimating personal exposure to solar ultraviolet radiation. Photochem Photobiol 84, 371-375.

7. CIE Standard (1998) Erythema Reference Action Spectrum and Standard Erythema Dose. CIE S OO7/E-1998. Vienna: Commission Internationale de l'Éclairage.

8. Diffey BL (2011) An overview analysis of the time people spend outdoors. Br J Dermatol 164, 848-854.

9. Lund CC \& Browder NC (1944) The estimation of the areas of burns. Surg Gyn Obs 79, 352-358.

10. Bogh MKB, Schmedes AV, Philipsen PA, et al. (2011) Interdependence between body surface area and ultraviolet $B$ dose in vitamin $\mathrm{D}$ production: a randomized controlled trial. Br J Dermatol 164, 163-169.

11. Langdahl JH, Schierbeck LL, Bang UC, et al. (2012) Changes in serum 25-hydroxyvitamin D and cholecalciferol after one 
whole-body exposure in a commercial tanning bed: a randomized study. Endocrine 42, 430-435.

12. Holick MF (2004) Sunlight and vitamin D for bone health and prevention of autoimmune diseases, cancers, and cardiovascular disease. Am J Clin Nutr 80, 6 Suppl., 1678S-1688S.

13. Clements MR, Davies M, Hayes ME, et al. (1992) The role of 1,25-dihydroxyvitamin $\mathrm{D}$ in the mechanism of acquired vitamin D deficiency. Clin Endocrinol 37, 17-27.

14. Lips P (2009) The relative value of $25(\mathrm{OH}) \mathrm{D}$ and 1,25(OH)2D measurements. Endocr Abstr 20, ME11.

15. Macdonald HM, Mavroeidi A, Fraser WD, et al. (2011) Sunlight and dietary contributions to the seasonal vitamin D status of cohorts of healthy postmenopausal women living at northerly latitudes: a major cause for concern? Osteoporos Int 22, 2461-2472.

16. Rhodes LE, Webb AR, Fraser HI, et al. (2010) Recommended summer sunlight exposure levels can produce sufficient $\left(\geq 20 \mathrm{ng} \mathrm{ml}^{-1}\right.$ ) but not the proposed optimal $\left(\geq 32 \mathrm{ng} \mathrm{ml}^{-1}\right.$ ) $25(\mathrm{OH}) \mathrm{D}$ levels at UK latitudes. J Invest Dermatol 130, $1411-1418$

17. Ilahi M, Armas LAG \& Heaney RP (2008) Pharmacokinetics of a single, large dose of cholecalciferol. Am J Clin Nutr 87, 688-691.

18. Vieth R, Chan PCR \& MacFarlane GD (2001) Efficacy and safety of vitamin D3 input exceeding the lowest observed adverse effect concentration. Am J Clin Nutr 73, 288-294.

19. Heaney RP, Davies KM, Chen TC, et al. (2003) Human serum 25-hydroxycholecalciferol response to extended oral dosing with cholecalciferol. Am J Clin Nutr 77, 204-210.

20. Byrne PM, Freaney R \& McKenna MJ (1995) Vitamin D supplementation in the elderly: review of safety and effectiveness of different regimes. Calcif Tissue Int 56, 518-520.

21. Chapuy MC, Arlot ME, Duboeuf F, et al. (1992) Vitamin D3 and calcium to prevent hip fractures in elderly women. $N$ Engl J Med 327, 1637-1642.

22. Chapuy M-C, Preziosi P, Maamer M, et al. (1997) Prevalence of vitamin D insufficiency in an adult normal population. Osteoporos Int 7, 439-443.

23. Krall EA, Sahyoun N, Tannenbaum S, et al. (1989) Effect of vitamin D input on seasonal variations in parathyroid hormone secretion in postmenopausal women. $N$ Engl $J$ Med 321, 1777-1783.

24. Kyriakidou-Himonas M, Aloia JF \& Yeh JK (1999) Vitamin D supplementation in postmenopausal black women. J Clin Endocrinol Metab 84, 3988-3990.

25. Cashman KD, Hill TR, Lucey AJ, et al. (2008) Estimation of the dietary requirement for vitamin $\mathrm{D}$ in healthy adults. Am J Clin Nutr 88, 1535-1542.

26. Henderson L, Irving K, Gregory J, et al. (2003) The National Diet and Nutrition Survey: Adults Aged 19 to 64 years Vitamin and Mineral Intake and Urinary Analytes. London: The Stationery Office.

27. Hyppönen E \& Power C (2007) Hypovitaminosis D in British adults at age $45 \mathrm{y}$ : nationwide cohort study of dietary and lifestyle predictors. Am J Clin Nutr 85, 860-868.
28. Dlugos DJ, Perrotta PL \& Horn WG (1995) Effects of the submarine environment on renal stone risk factors and vitamin D metabolism. Undersea Hyperb Med 22, 145-152.

29. Schlichting CL, Styer DJ (1989) Vitamin D Status of Submariners During Patrol. Groton, CT: Naval Submarine Medical Research Laboratory (January 1989; Report no. 1129).

30. Preece MA, Tomlinson S, Ribot CA, et al. (1975) Studies of vitamin D deficiency in man. Q J Med 44, 575-589.

31. Gilman SC, Biersner RJ \& Bondi KR (1982) Effect of a 68-day submarine patrol on serum 25-hydroxyvitamin D levels in healthy men. Int J Vitam Nutr Res 51, 63-67.

32. Holy X, Collombet JM, Labarthe F, et al. (2012) Effects of seasonal vitamin $\mathrm{D}$ deficiency and respiratory acidosis on bone metabolism markers in submarine crewmembers during prolonged patrols. J Appl Physiol 112, 587-596.

33. Luria T, Matsliah Y, Adir Y, et al. (2010) Effects of a prolonged submersion on bone strength and metabolism in young healthy submariners. Calcif Tissue Int 86, 8-13.

34. Smith SM, Wastney ME, Morukov BV, et al. (1999) Calcium metabolism before, during, and after a 3-mo spaceflight: kinetic and biochemical changes. Am J Physiol 277, R1-R10.

35. Pearce SHS \& Cheetham TD (2010) Diagnosis and management of vitamin D deficiency. Br Med J 340, 142-147.

36. Springbett P, Buglass S \& Young AR (2010) Photoprotection and vitamin D status. J Photochem Photobiol B: Biol 101, $160-168$.

37. Schmalwieser AW, Enzi C, Wallisch S, et al. (2010) UV exposition during typical lifestyle behavior in an urban environment. Photochem Photobiol 86, 711-715.

38. Thieden E, Philipsen P, Heydenreich J, et al. (2004) UV radiation exposure related to age, sex, occupation, and sun behavior based on time-stamped personal dosimeter readings. Arch Dermatol 140, 197-203.

39. Norval M, Björn LO \& de Gruijl FR (2010) Is the action spectrum for the UV-induced production of previtamin $\mathrm{D}_{3}$ in human skin correct? Photochem Photobiol Sci 9, 11-17.

40. Bouillon R, Eisman J, Garabedian M, et al (2006) Action Spectrum for Production of Previtamin $D_{3}$ in Human Skin. Vienna: Commission Internationale de l'Eclairage (CIE) Central Bureau (CIE Technical Report 174).

41. Macdonald HM, Mavroeidi A, Barr RJ, et al. (2008) Vitamin D status in postmenopausal women living at higher latitudes in the UK in relation to bone health, overweight, sunlight exposure and dietary vitamin D. Bone 42, 996-1003.

42. Webb AR, Kift R, Durkin MT, et al. (2010) The role of sunlight exposure in determining the vitamin $\mathrm{D}$ status of the U.K. white adult population. Br J Dermatol 163, 1050-1055.

43. McKenzie R, Scragg R, Liley B, et al. (2012) Serum 25-hydroxyvitamin-D responses to multiple UV exposures from solaria: inferences for exposure to sunlight. Photochem Photobiol Sci 11, 1174-1185.

44. Hillis WD (1993) Why physicists like models and why biologists should. Curr Biol 3, 79-81. 